\title{
ALGUNS ASPECTOS ESTRUTURAIS DAS CÉLULAS CRISTALIF́FERAS DE Cariniana integrifolia Ducke.
}

(Lecythidaceae)

Paulo Cesar Botosso

Centro de Pesquisas de Produtos Florestais (CPPF). Instituto Nacio nal de Pesquisas da Amazōnia (INPA). Manaus, AM.

Josē Wilson Meirelles

Centro de Microscopia Eletrónica do Departamento de Patologia Tropi cal. Instituto Nacional de Pesquisas da Amazōnia (INPA). Manaus, AM.

\section{RESUMO}

De acordo com a presença de cēlulas cristalîferas no parên quima axial de Tauari (Cariniana integrifozia Ducke, Lecythidaceae), procurou-se caracterizar o tipo e a configuração destas células em relação a alguns padrões referidos para outros taxons da famīlia. observações realizadas à nîvel de microscopia eletrōnica de trans missão revelaram a presença de paredes transversais normais separan do as unidades cristalifferas. Neste sentido, a configuração estrutu ral deste caracter mostrou-se de alguma significāncia taxonómica além de valor diagnóstico. Em base destas observações, a terminologia de cēlulas cristalîferas (stricto sensu) è discutida.

\section{SUMMARY}

BOTOSS0, P.C. and MEIRELLES, J.W., 1987. Some structural aspects of crystalliferous cells of Cariniana integrifolia Ducke. (Lecythidaceae). Ciência e Natura, 9:121-128,1987.

According to the presence of crystalliferous cells in axial wood parenchyma of Tauari (Cariniana integrifolia Ducke, Lecy thidaceae) an attempt was made to characterize these cells in relation to some patterns refered to other Lecythidaceous taxa. 0 b servations at the transmission electron microscopy level revealed the presence of normal cross walls separating the individual crystalcontaining units. In this context, the structural configuration of these cells proved to be of some taxonomic significance in addition to their diagnostic value. The terminology of the crystalliferous cells (stricto sensu) is discussed.

INTRODUÇAOO

Diversos aspectos de interesse acerca da formação, estru tura e função da presença de cristais de oxalato de cālcio nas plan tas tem sido extensivamente abordado por FRANCESCHI \& HORNER (2). Se gundo PARAMESWARAN \& RICHTER (4), enquanto que a maioria dos traba lhos realizados referem-se à presença destas inclusões inorgānicas (sîlica e cristais de oxalato de cälcio) em partes vegetais, tais 
como folhas e partes reprodutivas, poucos são os referentes a madei ra e casca.

Para RICHTER (5), o padrão de distribuição e o arranjo par ticular destas inclusões inorgānicas para Lecythidaceae tem demons trado o seu valor diagnóstico e de significāncia taxonōmica repeti damente à nīveis especīficos, genéricos e de famỉlia.

Com relação a esta famîlia, o interesse na anatomia da ma deira e em detalhes estruturais dos diferentes taxons reside na pos sibilidade de distingu $\bar{i}-10 s$ através de suas inclusões inorgânicas, especialmente sîlica e monocristais de oxalato de cálcio. Segundo RICHTER (5), o uso destas. caracteristicas parece ser um meio seguro para a identificação das madeiras de Couratari e Couroupita as quais são, por outro lado, macroscopicamente similares. PARAMESWARAN \& RICHTER (4), baseando-se numa classificação à nīvel de microscopia ótica dos gēneros de Lecythidaceae, de acordo com a presença de cé lulas cristalíferas, procuraram caracterizá-las à nīvel de ultraestrutura. Os mesmos constataram que, o tipo e a configuração mos trada permitem que os gêneros sejam agrupados com respeito a ocor réncia dos cristais de oxalato de Ca, sendo de significância taxonó mica alëm de valor diagnōstico para a famīlia. Esta caracterização permitiu o agrupamento dos gêneros Azzantoma, Berthozzetia, Coritho phora e Couratari como pertencendo a uma mesma categoria, e outra englobando os gêneros Grias, Couroupita e Gustavia.

Este trabalho tem como objetivo caracterizar o tipo e a configuração estrutural das cēlulas cristalíferas de Cariniana inte grifolia Ducke, segundo os padrões referidos por PARAMESWARAN \& RICHTER (4) para a familia. Da mesma forma, a terminologia existen te (stricto sensu) para este padrão estrutural é discutida.

\section{MATERIAL E METODOS}

Foram examinadas amostras de madeira provenientes de 3 individuos de Tauari (Cariniana integrifolia Ducke, Lecythidaceae). A princīpio, visando caracterizar o tipo destas células cristalife ras presentes à nível de microscopia ōtica, foram obtidas secções transversais e longitudinais tangencial e radial através de micróto mo de deslizamento. A dissociação do material foi realizada empre gando-se o método de Jeffrey, citado por BERLYN \& MIKSCHE (1). As secções anatómicas foram coloridas com safranina e azul de astra e preparadas em lâminas permanentes com "Permount". A terminologia em pregada segundo o estabelecido pela Associação Internacional de Ana tomistas de Madeira (IAWA, 3).

Para microscopia eletrōnica de transmissão foram selecio nadas somente as āreas contendo células cristalîferas tīpicas, ba seadas nas observações à nīvel de microscopia ōtica. 0 material re cém-preparado foi submetido à aspiração a vācuo por um perīodo de 
duas horas. Posteriormente, o mesmo foi fixado numa solução aquosa $2 \%$ de $\mathrm{KMnO}_{4}$ por 5 horas no escuro (geladeira). Após a desidratação em série ascendente de acetona, as amostras foram embebidas numa mis tura de acetona/resina Epoxy nas seguintes proporções: 2:1; 1:1 e 1:2. Em seguida, colocadas em resina pura e mantidas por 3 dias em estufa a $60^{\circ} \mathrm{C}$ para polimerização. As secções ultra-finas obtidas em ultra-micrótomo Reichert 0m U3 foram, subsequentemente, contrasta das com citrato de chumbo e examinadas em microscópio eletrōnico de transmissão modelo Zeiss em 10-A.

RESULTADOS

Quando se observa em secção transversal o aspecto geral da estrutura anatōmica da madeira de Cariniana integrifolia Ducke verifica-se, no que diz respeito ao parēnquima axial (Figura 1), um

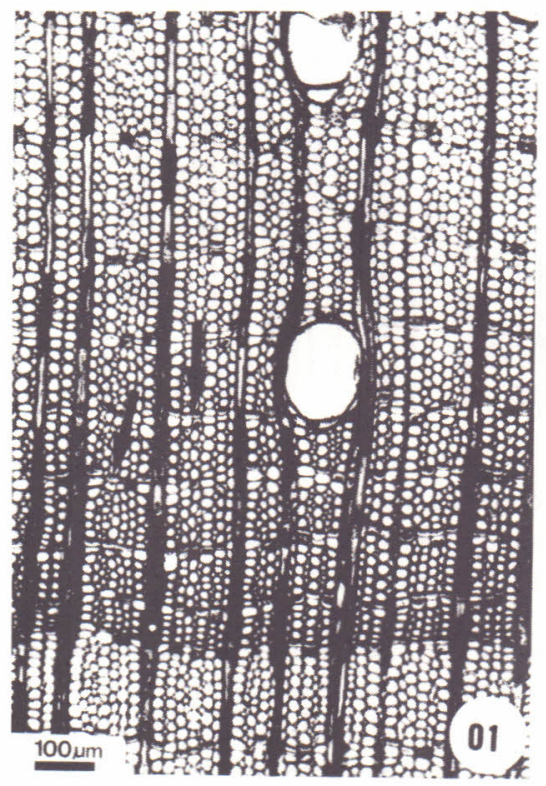

Figura 1 - Seç̧ão transversal da madeira de Cariniana integrifolia Ducke, mostrando a ocorrência de células cristalîferas adjacentes às fibras (setas).

modelo tipicamente apotraqueal em finas faixas geralmente unisseria das, às vezes, bisseriadas constituindo um padrão escalariforme com faixas regularmente espaçadas, exceto nas proximidades dos limites das camadas de crescimento onde este espaçamento torna-se relativa mente variāvel. Associado a estas finas faixas de cēlulas de parēn quima axial observam-se fileiras uni, ocasionalmente, bisseriadas 
de células cristalïferas podendo constituir sēries verticais com 50 a 100 unidades (Figura 2); cada uma contendo pequenos monocristais de oxalato de cálcio. Estas fileiras de células cristalíferas loca lizam-se, invariavelmente, em posição adaxial (interna) às células do parēnquima axial.

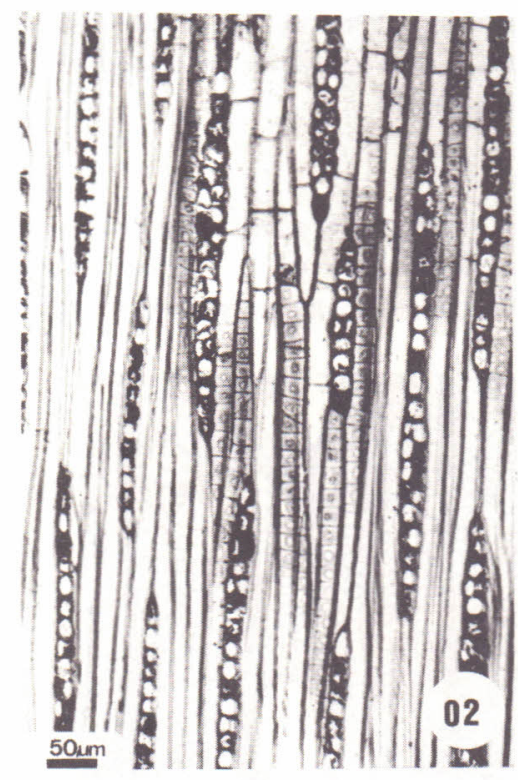

Figura 2 - Secção longitudinal tangencial da madeira de Cariniana integrifolia Ducke com unidades cristaliferas formando longas séries verticais.

Estas cēlulas cristalîferas apresentam, como um de seus aspectos característicos, um espessamento unilateral da parede da célula que contém o cristal (Figura 3), espessamento este adjacente à parede da fibra vizinha. No entanto, em relação a cêlula parênqui mática do lado oposto, tal espessamento inexiste. Durante a disso ciação do material, verifica-se que as unidades contendo estes mono cristais tendem a se separar individualmente.

$\bar{A}$ nivel de microscopia eletrônica de transmissão consta ta-se que este espessamento apresenta uma estrutura polilamelada (Figura 4). Os monocristais propriamente ditos estão incrustados nes te espessamento sendo que, freqdentemente, estão envolvidos por uma fina parede. Outra caracterîstica importante no tipo destas células cristalîferas está na parede que separa estas unidades cristalîfe ras (Figura 5). Estas paredes apresentam uma provāvel natureza de 


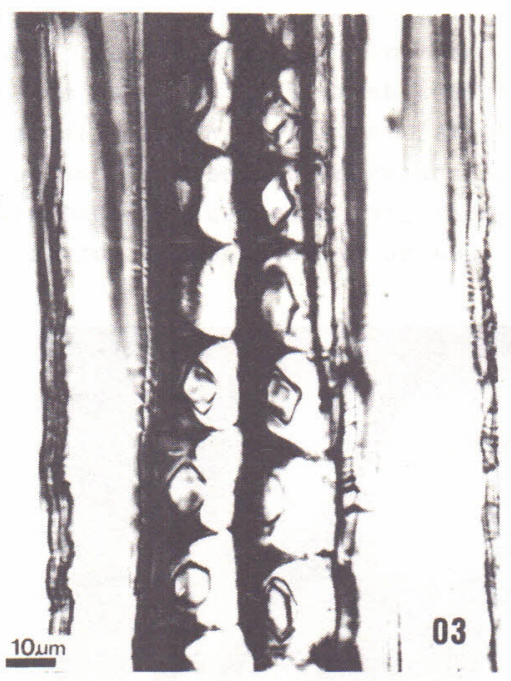

Figura 3 - Seç̧ão longitudinal radial mostrando séries cristalífe ras verticais no parénquima axial.

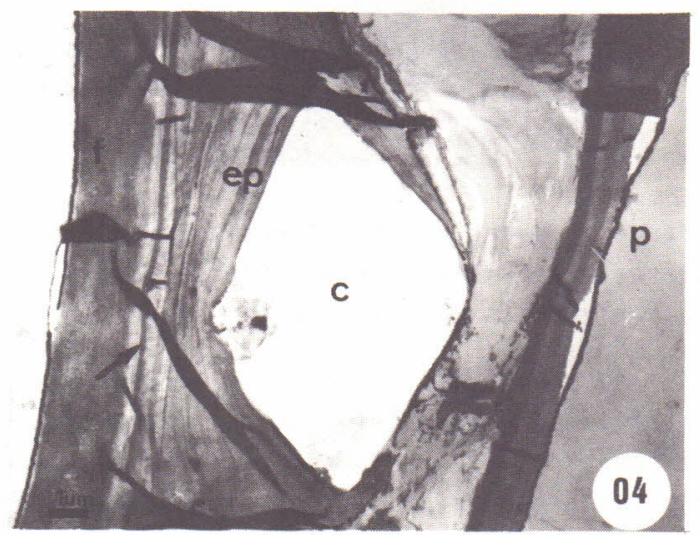

Figura 4 - Unidade contendo o monocristal (c) com espessamento poli lamelado unilateral (ep) adjacente à parede da fibra(f), tendo do lado oposto a cêlula de parênquima axial (p).

formação semelhante à lamela/parede primāria e estendem-se transver salmente de lamela à lamela média da célula-mãe.

DISCUSSOES E CONCLUSOES

A configuração destas sēries cristalīferas observadas em cariniana integrifolia corresponde as aspecto estrutural mencionado 
por RICHTER ( 5 ) e PARAMESWARAN \& RICHTER (4) para algumas espécies de diferentes taxons da familia Lecythidaceae. Segundo PARAMESWARAN \& RICHTER (4), os gêneros desta famillia podem ser agrupados com res peito a ocorrência destas inclusões inorgânicas nas células do pa rénquima axial. Neste contexto, o tipo e a configuração ęstrutural deste aspecto observados para esta espécie demonstram alguma signi ficância taxonômica, quando relacionados a outros taxons da famỉlia.

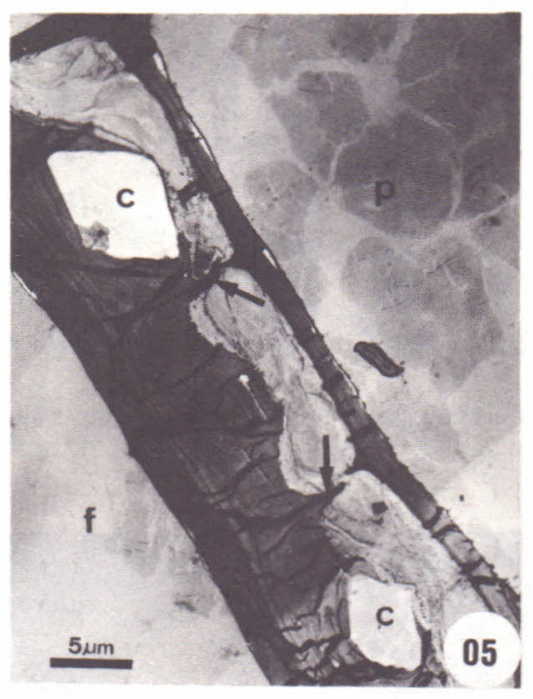

Figura 5 - Série de unidades cristalifferas mostrando a presença de pequenos monocristais de oxalato de cálcio (c) e pare des transversais normais (setas) separando as unidades.

Sob o ponto de vista taxonōmico, embora não conclusivo, este aspec to estrutural permitiria enquadrā-10 junto a outros taxons de Lec $\underline{y}$ thidaceae, tais como: Allantoma, Bertholletia, Corythophora e Coura tari (Figura 6). Contudo, a significância taxonômica deste caracter para o gênero Cariniana só seria possỉvel com o estudo de outras es pécies.

Em base das observações realizadas à nivel de microscopia eletrōnica de transmissão, alguns aspectos relacionados à terminolo gia existente para este tipo de estrutura devem ser reconsiderados.

Segundo a definição fornecida pelo glossārio da Associa ção Internacional de Anatomistas de Madeira (IAWA, 3 ), este detalhe estrutural corresponde às "séries cristalîferas em câmaras" na 1 ite ratura, cuja definição é: "célula cristalîfera dividida em comparti mentos por septos". Esta definição condiz com as fileiras de célu las cristaliferas em Cariniana integrifolia, desenvolvendo-se adjacente 
às fibras. Entretanto, a definição como referida no glossārio da IAWA (3) não é compatível ao verificado para esta espécie. Este as pecto é exposto e discutido por PARAMESWARAN \& RICHTER (4), para ou tros taxons de Lecythidaceae.

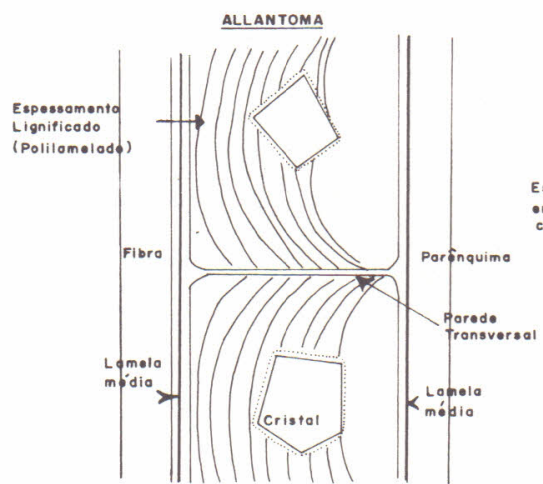

06

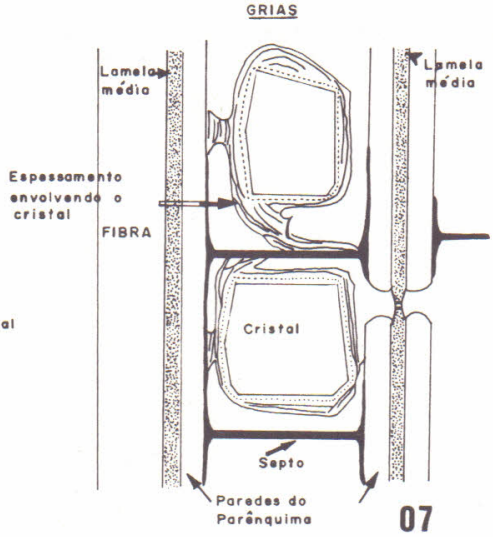

parenquimäticas

Figura 7 - Grias cristalïferas em AZzantoma Zineata. Figura 7 cauliflora, segundo PARAMESWARAN \& RICHTER (4).

Neste caso, ocorre uma parede transversal normal (Figuras 5 e 6$)$, aparentemente formada por divisão nuclear e estendendo-se, como no caso de células somáticas, através da cēlula-mãe. Desta for ma, o termo "septo" para Cariniana integrifolia, como referido à Grias (Figura 7), seria imprōprio. Em Grias estas paredes transver sais correspondem realmente aos "septos", as quais não estão conec tadas com a lamela média da cēlula-mãe. Assim, conīorme salientado por PARAMESWARAN \& RICHTER (4), dever-se-ia considerar cada unidade individual contendo o cristal como "cēlula". Em base disto, tornase evidente que sob resolução de microscopia ótica não podemos, fre qulentemente, definir o tipo destas células cristalïferas, como sen do uma sērie de câmaras individuais ou células de acordo com o tipo de parede transversal presente.

\section{REFERENCIAS BIBLIOGRĀFICAS}

1. BERLYN, G.P. \& MIKSCHE, J.P. Botanical Microtechnique and Cyto chemistry. Iowa State University Press, Ames, Iowa. 1976. 326p.

2. FRANCESCHI, V.R. \& HORNER, Jr., H.T. Calcium oxalate crystals in plants. Bot. Rev., 46:361-427. 1980.

3. IAWA Committee on Nomenclature. Multilingual glossary of terms used in wood anatomy. Konkordia, Winterthur. 1964. 186 p. 
4. PARAMESWARAN, N. \& RICHTER, H.G. The ultrastructure of crystalli ferous cells in some Lecythidaceae with a discussion of their terminology. IAWA Bulzetin n.s., vol. 5(3):229-236, 1984.

5. RICHTER, H.G. The wood structure of Couratari Aubl. and Couroupi ta Aubl. (Lecythidaceae). IAWA Bulletin n.s. 3(1):45-55. 1982.

Recebido em setembro, 1987; aceito em outubro, 1987. 